\title{
REQUERIMIENTOS DE CONFIRMACION DE INCAUTACION EN CASO DE INTERVENCIONES EN DELITOS FLAGRANTES
}

\author{
Garay MerCado, Martin Pedro ${ }^{124}$
}

SUMARIO: 1. Introducción. - 2. La incautación en el Nuevo Código Procesal Penal. 3. Conclusión.

\section{Introducción}

El Código Procesal Penal, introduce nuevas instituciones procesales, como es la confirmatoria de la incautación en los casos de comisión de delitos en situación de flagrancia, la misma que obliga al Ad quo -Fiscal encargado del caso, a solicitar la confirmatoria de la incautación realizada por el personal policial al momento de realizado la intervención policial por flagrancia delictiva; siendo así, el presente tema nos dilucidará sobre la solicitud del Fiscal y procedimiento a tratar de esta institución; y cuál sería las consecuencias si no se solicitó la confirmación de incautación antes de terminado la segunda etapa del proceso común -Investigación Preparatoria.

\section{La incautación en el Nuevo Código Procesal Penal}

La Incautación. Es una medida limitativa de derechos en la Investigación Preliminar y Preparatoria, porque colisiona con los derechos fundamentales de las personas, que en el caso concreto sería el derecho de propiedad, reconocida en el inciso 16 del artículo $2^{\circ}$ de la Constitución Política del Estado peruano. Siendo así, es un acto que el Estado está facultado para realizar a través de las autoridades de administración de justicia previo un procedimiento, en tal sentido se le puede entender también como el decomiso de los bienes, instrumentos o cosas de una persona imputada de la comisión de un delito, o de los instigadores o los cómplices hayan utilizado para la comisión de un delito determinado o también a lo referente del producto del acto delictivo.

Al decir de Roberto Eduardo Cáceres Julca, el secuestro y/o incautación consisten en el apoderamiento forzoso por parte de la autoridad del Ministerio Público de los objetos del delito o los instrumentos con los que se hubiere ejecutado, así como los efectos, sean estos bienes, dinero, ganancias o cualquier producto proveniente del delito, así se encuentre en poder de personas naturales o jurídicas $[1]$.

Ahora los objetos del delito, instrumentos o efectos del delito a decir del mismo autor son:

Objeto del delito: Se trata las cosas sobre la que recae la acción del delito. Por ejemplo los caudales o recursos públicos (peculado, malversación, colusión etc.) [2] de Huánuco

${ }^{124}$ Fiscal Adjunto Superior adscrito a la Cuarta Fiscalía Superior Penal de Apelaciones Distrito Judicial 
Instrumentos del delito: Son los elementos materiales que se utilizan en la ejecución de la acción.

Efectos del delito: Son los productos o beneficios que se obtiene de la comisión del delito, dentro de este concepto encontramos los bienes, dinero, ganancias o cualquier otro derivado directa o indirectamente del delito. [3]

La incautación, en cuanto medida procesal, presenta una configuración jurídica dual: como medida de búsqueda de pruebas y restricción de derechos propiamente, medida instrumental restrictiva de derechos (artículos $218^{\circ}$ al $223^{\circ}$ del Nuevo Código Procesal Penal), y como medida de coerción con una típica función cautelar (artículos $316^{\circ}$ al $320^{\circ}$ del NCPP). En ambos casos es un acto de autoridad que limita las facultades de dominio respecto de bienes o cosas relacionados, de uno u otro modo, con hecho punible. En el primer caso, su función es primordialmente conservativa - de aseguramiento de fuente de prueba material, y luego probatoria que ha de realizarse en el juicio oral. En el segundo caso, su función es substancialmente de prevención de ocultamiento de bienes sujetos a decomiso y de impedimento a la obstaculización de la averiguación de la verdad.

La incautación instrumental recae contra los bienes que constituyan cuerpo del delito, o contra las cosas que se relacionan con el delito o que sean necesarias para el esclarecimiento de los hechos investigados. El objeto de esta medida de aseguramiento es amplio y, por su propia naturaleza investigativa, comprende una extensa gama de bienes u objetos relacionados, de uno u otro modo, con el delito. La incautación cautelar incide en los efectos provenientes de la infracción penal, en los instrumentos con los que se ejecutó y en los objetos del delito permitidos por la ley.

La incautación, instrumental o cautelar, es una medida que lo realiza, en primer término, la Policía o la Fiscalía, pero a continuación requiere de la decisión confirmatoria del Juez de la Investigación Preparatoria.

El artículo VI del Título Preliminar del Código Procesal Penal prescribe que las medidas que limitan derechos fundamentales, salvo las excepciones previstas en la Constitución solo podrán dictarse por la autoridad judicial, en el modo, forma y con las garantías previstas por la Ley. Se impondrán mediante resolución motivada, a instancia de la parte procesal legitimada. La orden judicial debe sustentarse en suficientes elementos de convicción; en atención a la naturaleza y finalidad de la medida y al derecho fundamental objeto de limitación, así como respetar el principio de proporcionalidad.

El artículo $218^{\circ}$ del Código Procesal Penal prescribe que la Policía no necesita autorización del Fiscal (refiriéndose a la incautación de bienes), ni orden judicial cuando se trata de una intervención en flagrante delito o peligro inminente de su perpetración de cuya ejecución dará cuenta inmediata al Fiscal.

Cuando existe peligro por la demora, la exhibición o la incautación debe disponerla el Fiscal. En todos estos casos, el Fiscal una vez que tomó conocimiento de la medida o dispuesto su ejecución, requerirá al Juez de la Investigación Preparatoria la correspondiente resolución confirmatoria [4]. 
Alonso Raúl Peña Cabrera Freyre [5], en la Exégesis del Nuevo Código Procesal Penal, desarrolla la institución en comento, y refiere en el segundo párrafo que la solicitud del Fiscal deberá estar debidamente fundamentada, conteniendo la necesidad de la medida, la relevancia del bien que se pretende incautar o exhibir de forma forzosa, tomando en consideración los fines que se persiguen en la investigación [...]

Asimismo, el cuarto párrafo del mismo texto precisa que "De otro lado cuando exista un peligro en la demora, la exhibición o incautación deberá imponerla el Fiscal”, en esta hipótesis, existe un riego fundado, de que el paso del tiempo puede perjudicar los fines de la investigación plasmados en la ejecución de la medida, sea cual fuere el caso; el Fiscal deberá requerir al Juez de la Investigación Preparatoria la correspondiente resolución confirmatoria. En definitiva, la legitimidad de cualquiera de estas medidas de injerencias reposa necesariamente en la convalidación judicial, sólo el órgano jurisdiccional -como actor imparcial- está en posibilidad de valorar la razonabilidad y necesidad de la medida, y sobre todo, la proporcionalidad de la medida.[6]

A través de esta medida se busca obtener y asegurar los bienes utilizados o vinculados a la comisión del delito. En este caso, el fiscal o la parte legitimada podrá requerir al juez de la investigación preparatoria la incautación [7] de los bienes vinculados al delito. Dicha solicitud debe demostrar que la libre disponibilidad de los bienes agrava, prolonga o facilita el delito. En la diligencia, el fiscal ordenará registrar, detallar, asegurar e inventariar los bienes. Esto deberá constarse en un acta, la cual será firmada por los participantes y testigos. Al concluir la audiencia, deberá de indicar la hora, identificar quienes han intervenido, designar al responsable de la custodia en el traslado, almacenamiento, administración y destino final de los bienes. Se entregarán copias certificadas del acta a los afectados.

La incautación de los bienes muebles se realiza tomando en custodia e inscribiéndose en el registro correspondiente. En el caso de inmuebles o derechos sobre ellos se toma posesión de ellos y se anota en el registro, es posible que las diligencias preliminares y en las investigaciones preparatorias formalizadas, el fiscal o la policía realicen la incautación de bienes sin contar con orden judicial cuando existan peligro por la demora. En este caso, el fiscal requerirá la confirmación judicial inmediata y El juez expedirá su resolución en el plazo de dos días.

Ahora, en los casos que se solicita la (requerimiento) confirmatoria de una incautación de objetos o instrumentos utilizados en los hechos materia del delito, se narra los hechos materia de investigación de forma detallada, describiendo los instrumentos utilizados al momento de la comisión del delito, referencia a la norma adjetiva que ampara la pretensión y se describe los elementos de convicción, acompañándose copia fedateada de las actas de incautación en el respectivo requerimiento, que describe claramente el lugar donde fueron encontrados los instrumentos del delito, quién lo incautó y en qué situación se realizó dicha diligencia, la misma que deberá ser solicitada inmediatamente ante el Juzgado de Investigación Preparatoria por parte del representante del Ministerio Público una vez tomado conocimiento. 


\section{Conclusión}

De la lectura del Código Procesal Penal del 2004 se advierte que no existe norma que determine cuál es el espacio temporal del que podría hacer uso el Fiscal para requerir la confirmatoria judicial de incautación inmediatamente, y es por ello que el término inmediatamente a la apertura del NCPP en varios distritos judiciales era interpretado indistintamente, pensando que ello podía entenderse como tan pronto como concluya el acto o en todo caso dentro de las veinticuatro horas de su realización, e inclusive los más osados manifestaban que aquel requerimiento podía realizarse tan pronto como las atareadas labores del representante del Ministerio Público lo permitan. A ello se debe que durante los primeros meses de vigencia del Código Procesal Penal, se haya optado por no confirmar judicialmente la incautación cuando el requerimiento postulado por el representante del Ministerio Público era presentado después de varios días de practicado la diligencia misma de incautación. Posteriormente surgió prácticamente una postura uniforme en el sentido de que si bien el Código Procesal Penal no hace mención al espacio temporal que tiene el Fiscal Provincial para requerir la confirmatoria judicial inmediatamente, ello podía interpretarse que la oportunidad de solicitar la confirmatoria era "el mismo día o a más tardar al día siguiente" de verificada la medida que precisamente es el plazo que otorga el Código Adjetivo en el artículo $203^{\circ} .3$ para que el Juez de Investigación Preparatoria se pronuncie al efecto y así también se dice en el art. $316^{\circ} .2$ del Código Procesal Penal cuando refiere:

Acto seguido, el Fiscal Provincial requerirá inmediatamente al Juez de la Investigación Preparatoria la expedición de una resolución confirmatoria, la cual se emitirá en el plazo de dos días...

Siendo así, por interpretación sistemática de las normas del propio Código Procesal Penal del 2004 se concluyó que si el Juez de Investigación Preparatoria tiene dos días para pronunciarse sobre el requerimiento Fiscal; en consecuencia, ese mismo plazo debía concederse al Fiscal para que válidamente pueda postular el respectivo requerimiento, dejándose constancia que ese plazo se computa sólo por días hábiles y a partir del momento en que el representante del Ministerio Público conocía del verificativo de la incautación por la policía o por otra entidad estatal como es el caso de Aduanas. Lo que sí quedó zanjado fue el hecho de que si el fiscal no presentaba el requerimiento de confirmatoria judicial de incautación dentro de las cuarenta y ocho horas y ello se advertía en el debate, la consecuencia lógica era que no se confirme judicialmente la incautación, consiguientemente sus alcances no podían ser utilizados como acto de investigación por el titular de la acción penal pública.

Otro problema que se presenta a menudo en distritos judiciales que se han implementado recientemente el Nuevo Código Procesal Penal, bienes que no fueron confirmados oportunamente, por lo que se está frente ante una prueba irregularmente obtenida -incautación de objetos o instrumentos del delito, en la cual no se respetó lo prescrito en el artículo $218^{\circ}$ inciso 2 del Código Procesal Penal, contraviniendo el artículo $8^{\circ}$ del Título Preliminar de la norma procesal, norma ésta que es de orden público, afectándose en consecuencia, la garantía constitucional del debido proceso a que tiene todo justiciable y por ende el derecho a la tutela jurisdiccional efectiva, previsto en el artículo $139^{\circ}$ inciso 3 de la Constitución Política del Perú. 
En ese sentido, en una Investigación Preparatoria donde el Fiscal responsable del caso (Fiscal Adjunto Provincial, Fiscal Provincial y/o Fiscal Coordinador -Corporativo), no haya solicitado diligente y oportunamente (lo antes posible para que el imputado y la parte agraviada puedan ejercer su derecho de defensa material) al Juez de la Investigación Preparatoria, la resolución confirmatoria de los objetos o instrumentos incautados, que constituyen cuerpo de delito, las mismas que son necesarias para el esclarecimiento de los hechos investigados, éstas no serán admitidas -ofrecimiento de pruebas- siendo rechazadas o desestimadas en el Etapa Intermedia durante la audiencia de Control de Acusación, por carecer de efecto legal de conformidad con el inciso 2 del artículo $8^{\circ}$ del Título Preliminar y artículo $159^{\circ}$ del Código Procesal Penal, esto es, por existir vulneración del contenido esencial de los derechos fundamentales de la persona, al no haberse obtenido en forma conducente o legal (prohibición probatoria).

Estando que con el transcurrir del tiempo y espacio, se vaya corrigiendo la labor del Fiscal; esto es, con una buena Gestión de Despacho Fiscal enmarcado en la Escuela Procesal postulada por el francés Henry Fayol, siendo uno de los procesos gerenciales: el planeamiento [8] implica que los administradores (Fiscal responsable del caso y/o Fiscal Coordinador) piensen con antelación en sus metas y acciones y que basan sus actos en algún método, plan o lógica, y no en corazonadas [...] la misma que los guiará al objetivo de sus planes $\mathrm{u}$ acciones, $\mathrm{y}$ si en caso cuando ésta no sea satisfactorio, se puedan tomar medidas correctivas.

En suma el Fiscal una vez puesto en conocimiento de incautación de documentos, objetos o cosas por parte de la intervención de efectivos policiales en flagrancia delictiva, inmediatamente solicitará al Juez, la confirmatoria de incautación fundamentando y anexando todo los medios y/o elementos de evidencia suficientes, la misma que conseguirá una prueba sólida en la Etapa de Juzgamiento que conllevara al éxito de la ejecución de la pena y su accesoria reparación civil, y por ende no será acreedor a responsabilidad administrativa por su tardanza o no presentación de la solicitud confirmatoria de incautación.

[1] El Proceso de Pérdida de dominio \& Las Medidas Cautelares en la Investigación Preliminar, Ideosa, 2008: 386.

[2] Artículos $382^{\circ}$ al $401^{\circ}$ Código Penal, Competencia de las Fiscalías Especializadas en Delitos de Corrupción de Funcionarios, Delitos Contra la Administración Pública-Delitos cometidos por funcionarios públicos, conforme al nuevo modelo procesal penal.

[3] El Proceso de Pérdida de dominio \& Las Medidas Cautelares en la Investigación Preliminar, Ideosa, agosto 2008: 387.

[4] Código Penal. Lima: Jurista Editores, 2009: 481

[5] Fiscal Adjunto Superior adscrito a la Primera Fiscalía Suprema Penal.

[6] Exegesis del Nuevo Código Procesal Penal, Lima: 2007: 604.

[7] Véase, artículos $316^{\circ}$ y $317^{\circ}$ del CPP de 2004.

[81 Stoner, James A.F., R. Edgard Freeman, Daniel A. Jilbert Jr.., Administración. 6a ed. México: Prentice Hall Hispanoamericana: 1999: 11. 


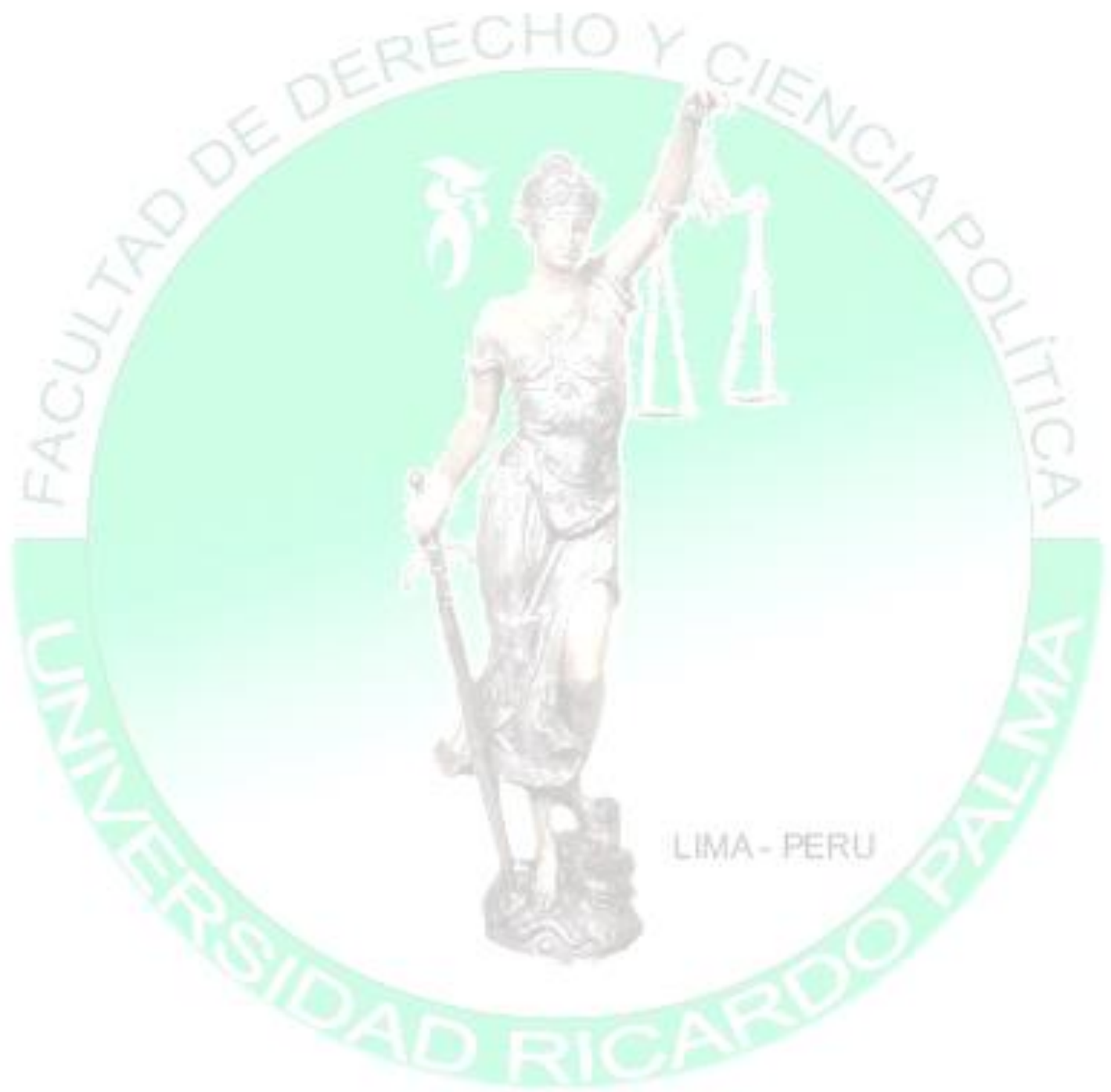

